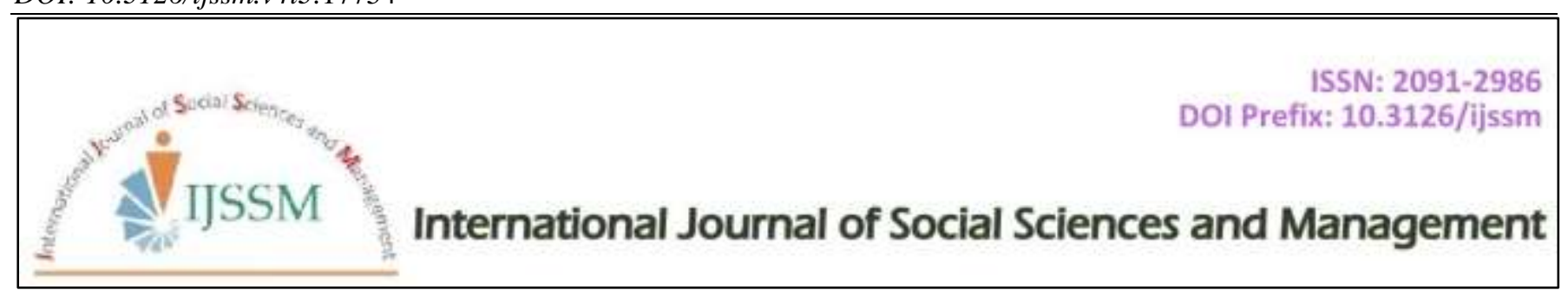

Research Article

\title{
Relation between Extent of Participation and Extent of Knowledge of Farm Women in Various Farms Practices
}

\author{
R. Mishra* and A.K. Gupta* \\ Department of Technology Transfer, Mahatma Gandhi Chitrakoot Gramoday Viswavidyalay Satna, M.P. India \\ *Correspondence author email: rudrajay@gmail.com
}

\begin{abstract}
Agriculture is an important part of India's economy and at present it is among the top two farm producers in the word. This sector provides approximately present of the total number of jobs available in India and contributes around 13.5 percent to the GDP. Agriculture is the only means of living for almost two-thirds of the employed class in India. As being stated by the economic data of financial 2014-15, agriculture has acquired 13.5 percent of India's GDP. The agriculture sector of India has occupied almost 43 percent of India's geographical area agriculture play a vital role in the in the Indian economy over 70 percent of the rural house hold depend on agriculture. Agriculture is an important sector of Indian economy as it contributes about 60 percent job the population. the food grain protection has form 57 million tons (MT) in 1950-57 to268MT during 201314 highest ever since independence. In the years since its independence, India has made immense progress towards food security. Indian population has tripled, and food - grain production more than quadrupled. There has been a substantial increase in available food-grain per capita. Present study was carried out in two blocks of district Satna with 120 farmwomen. Eight farm practices were selected after the consultation with officials and farmwomen. Correlation coefficient was used to find out relation between extent of knowledge and extent of participation of the farmwomen with regard to the practices. It was found that there is a equal variables positive and negative, significance and non-significant relationship between participation and knowledge of the respondents.
\end{abstract}

Keywords: Participation; knowledge; farmwomen.

\section{Introduction}

Agricultural modernization means from traditional agriculture to modern agriculture transformation process. Modernization requires sophistication in mechanization, which is possible at relatively large scales of operations with capital and management constraints overcome. Marginal and small farmers are increasingly becoming part time, with absentee farmers, per urban farmers, wage earners on a part or full time basis. Industry and service sectors, trade and commerce unable to reduce land based livelihoods compel rural people to remain on land based livelihoods, forcing a stead y increase in the number of land holdings but with average land holdings going down making mechanization more challenging and difficult. Scaling down of farm machines reduces mechanical advantages. Instead of owning farm machinery y other than hand tools, such marginal farms can meet their needs through custom servicing. (If it is well developed).
Women's role in agricultural operations, animal husbandry and other economically productive activities are very significant. They contribute about $60-70$ percent of the labor required for these activities thus playing a pivotal role in sustaining economy (Singh, 2008). The decision making process is an important segment of every household because it makes implementation of a plan or programmed quit easy. In rural areas of the country, both husband and wife are jointly responsible for making decisions on matters like family obligations, specific housing charges and purchase of house hold articles. However, women s suggestions are not given due consideration in the decisions pertaining to agricultural sector and important family matters. It is because the majorities of women are illiterate, have little time to know about latest techniques of farming and restricted mobility due to several cultural taboos. we generally talk women s empowerment, which can be said that said that women should have powers to have an 
authority to make decisions and guide their destiny. their power in decision making can be acquired and exercised only if they have a thorough knowledge about the various programmed, plans and current issues, access to the basic human development and social policies. Generally, women have less access to information about technology by virtue of their inferior educational status and relative isolation from public life. Thus, there is a hesitation to come out and interact. At time, even the suggestions of knowledgeable rural women are ignored or are not taken seriously because men consider it disgraceful to accept the decision of women. This is because traditionally men have been major lawmakers of society. Many policies neglect women and undermine their abilities and roles (Bala, 2003).

The undesired restrictions imposed by elderly people in the society on their daughters and daughters -in -law should be relaxed to facilitate their mobility in order to have easy access to the outer world. Most importantly, the women should have a penchant for self -empowerment through enhancing their knowledge and skill. Empowerment without any change in man an attitude or without their willingness will only aggravate family problems, increasing dissatisfaction and ensuring that women will continue to be at the receiving end. Government policies should be framed to provide legal support and instill confidence in women. Programmed should be development exclusively for women; to build leadership skill for managing agricultural community based development activities. Access of technology, inputs and credit has to be ensured predominantly through women extension workers. They should be trained in farm management skill and made capable of taking even complex decision like shifting from subsistence farming to diversified agriculture, with stand competition from market forces improvement in work or from efficiency etc. The extant of participation in the decision -making activities in house hold and agriculture related and other sociocultural affairs reflects the status of woman in the family as well as society. That major decision regarding purchase of every household item is taken by males. Decisions in matters of food and clothing more or less have an equal participation rate between males and females. However, decision regarding saving and investments and purchase of household assets is taken by males i.e. 83.5 percent and 81.3 percent respectively as the male members control the finance, this creates an adverse impact on women's access to household assets and others house hold activities (Chaudhary, 2004). The major decision makers in agricultural activities are men even though women perform more in agricultural related activities than men. Even they need not be consulted at the time of purchase of animals or change of crop villages. There were no snakes or rats left in the plantations as all these had been caught and eaten by hungry workers. A shocked supreme court had sought the West Bengal government, response on an expert panel s report, which said that deaths due to starvation among workers of abandoned tea garden have assumed disastrous proportions. The overall farming performance is the farming productivity behavior of farm women comprising six components viz. cropping, intensity, cropping yield index, milk yield index, level of adoption, commercialization index and expansion /diversification index when compared to medium and large woman. However, in case of milk yield index, small form women are on par with medium but higher than the large farmwoman. (Reddy, 2003).

Keeping in view the above facts into consideration, the present investigation was undertaken with the fallowing objectives:

\section{Objectives}

i. To study the extent of knowledge of farm women in various agricultural operation.

ii. To assess the extent of participation of farm women in various farms activities.

iii. To find the relationship between extent of knowledge and extent of participation of the farm women in various agricultural operation.

\section{Plan of Work}

Satna district was selected for the study purpose. District Satna consist of eight blocks. Out of eight blocs two blocks have been selected randomly. For the selecting the villages, a list of all villages of selected blocks was the prepared and five villages were selected randomly from each block. The name of villages selected for the study were (1) Paldev (2) Pindra (3) Tendipatwania (4) Lalpur (5) Devlaha from Manjhgawan block and (1) Pahadi (2) Beldwara (3) Itma (4) Dhatura (5) Kherwa from Maihar block. For the selection of respondents, lists of all the categories of farm women were prepared and selected 3\% farmers from each village by the help of proportionate random sampling method. Thus, total 120 farmers have been selected for the present study. For the collection data well-structured schedule and scales have been used and information were collected through interview method. For statistical analysis average, Percentage, standard deviation and correlation coefficient were used. The consultation with officials and farm women eight extent of knowledge criteria have been selected i.e., farming pattern, seed selection, irrigation system, mechanization, fertilizers, plant protection measures, storage and capital respectively.

\section{Results and Discussion}

The results of the investigation carried out are presented through the table-1 showing correlation coefficient between extent of participation and extent of knowledge of farm women. 
It is clear from the data presented in the Table-1 that in case of participation of farm women in all activities of the family, the highest percentage of participation (40\%) in medium participation was reported by the respondents regarding the day by day activities. The 37 percent respondent's participation in low participation and 23 percent respondents of participation had high participation. The caste system of the area is closely related to the participation of farm women in family activities. The scheduled tribes farm women and scheduled caste farm women participation is better than general and other backward caste farm women. The lowest rank of general caste women in participation.

Table 1: Extent of participation

\begin{tabular}{|l|l|l|l|}
\hline \multirow{2}{*}{ S.N. } & Categories & \multicolumn{2}{|c|}{ Respondents } \\
\cline { 3 - 4 } & & Number & Percentage \\
\hline 1. & High Participation & 28 & 23.00 \\
\hline 2. & Medium Participation & 48 & 40.00 \\
\hline 3. & Low Participation & 44 & 37.00 \\
\hline Total & 120 & 100.00 \\
\hline
\end{tabular}

Table 2: Knowledge of farmwomen in various farms practices

\begin{tabular}{|l|l|l|l|}
\hline S.N. & Categories & \multicolumn{2}{|c|}{ Respondents } \\
\cline { 3 - 4 } & & Number & Percentage \\
\hline 1. & Low (up to 19) & 14 & 12.37 \\
\hline 2. & Medium (20 to 33) & 81 & 66.63 \\
\hline 3. & High (34 and above) & 25 & 21.00 \\
\hline & Total & 120 & 100.00 \\
\hline
\end{tabular}

Min-10, Max- 44, Mean-26.98, S.D.-7.44

It becomes clear that (Table 2) the maximum number of farmwomen knowledge about agricultural modernization had belonging medium categories $(66.63 \%)$ followed by high categories $(21 \%)$ and low categories (12.37\%). The respondents asked fifty questions from eight different fields like farming pattern, seed selection, irrigations systems, fertilizers, plant protection measures, mechanizations, stores and capital. The respondents had a good knowledge from farming pattern, irrigation system, mechanization and stores sections but plant protection measures, fertilizers, seed selection and capital section knowledge had poor of the respondent. The categories design for the formula of Mean - S.D., Mean \pm S.D. and Mean + S.D. respectively.

It is clear from the Table 3 that out of 8 criteria of knowledge of farm women, the correlation coefficient of three criteria viz. farming pattern (0.210263), mechanization (0.220936) and storage (0.252194) was statistically found to be positively and significantly correlated with involvement at 0.05 level of significance. Whereas, four criteria viz. seed selection (-0.159739), fertilizers (-0.345263), plant protection measures ($0.366017)$ and capital $(-0.360319)$ was found to be negatively and non-significant only one criteria irrigation system (0.0369980) found to be positive but nonsignificant. The above discussion leads to be concluded that the farming pattern, irrigation system mechanization and storage practices knowledge of farm women is effected by the involvement of farm practices. The four criteria like seed selection, fertilizers, plant protection measures and capital practices knowledge are not affected by the involvement of farm practices.

Table 3: Correlation coefficient between extent of participation and extent of knowledge of farmwomen.

\begin{tabular}{|l|l|l|}
\hline S.N. & Variables & Correlation Coefficient(r) \\
\hline 1 & Farming pattern & $0.210263^{*}$ \\
\hline 2 & Seed selection & -0.159739 \\
\hline 3 & Irrigation system & 0.0369980 \\
\hline 4 & Mechanization & $0.220936^{*}$ \\
\hline 5 & Fertilizers & -0.345263 \\
\hline 6 & Plant protection measures & -0.366017 \\
\hline 7 & Storage & $0.252194 *$ \\
\hline 8 & Capital & -0.360319 \\
\hline & & \\
\hline
\end{tabular}




\section{Conclusion}

It can be concluded that the farming pattern, mechanization and storage practices to be found a positive relationship with knowledge and participation of farm women in the area. The seed selection, fertilizers, plant protection measures and capital knowledge had negative with relationship of knowledge and participation and irrigation system knowledge had positive but non-significance of the area.

\section{Reference}

Bala B (2003) Rural women work only, they don't take decision. Tribune $20^{\text {th }}$ September, 2003, New Delhi.

Chaudhary S (2004) Invisible Activities of Rural Women. Kurukshetra 52(9)

Reddy G (2003) Forming performance of farmwomen 2003. Concept Publishing Company, New Delhi.

Singh S (2008) Agricultural Mechanization Policy. Proceedings of Tractors \& Farm Machinery Manufacturers Meet, Nov. 16-17, 2007, CIAE, B HOPAL. 